\title{
Saberes da tradição popular e da academia na formação do Professor de Teatro: o projeto da Ufal
}

\begin{abstract}
Knowledge of the popular tradition and academy in the formation of the Theater teacher: the project of Ufal
\end{abstract}

Marcelo Gianini ${ }^{1}$ 


\section{Resumo}

Apresentação e problematização do Projeto Pedagógico do Curso de Teatro Licenciatura, da Universidade Federal de Alagoas, que propõe, na formação do Professor de Teatro para a Educação Básica, o diálogo entre os conhecimentos acadêmicos com as manifestações espetaculares da tradição popular brasileira. Trata-se de proposição pedagógica do Colegiado deste curso, formulada em uma perspectiva ampliada do teatro e que pode ser significativa para o ensino e a aprendizagem da linguagem teatral no Brasil. A problematização se faz a partir das reflexões sobre cultura, da etnóloga Manuela Carneiro da Cunha, e do conhecimento tácito do artífice, do filósofo Richard Sennett.

Palavras-chave: Pedagogia do teatro; cultura popular; projeto pedagógico de curso; formação do professor de teatro; licenciatura em teatro

\section{Abstract}

The presentation and scrutinization of the Pedagogical Project of the Graduation Theater Course, in Universidade Federal de Alagoas, which proposes, in the formation of the Theater Teacher for Basic Education program, the dialogue between academic knowledge and the spectacular manifestations of Brazilian popular tradition. It is a pedagogical proposition of the Collegiate of this course, formulated in an extended perspective of the theater and that can be significant for the teaching and learning of theatrical language in Brazil. The scrutinization is made from the reflections on culture, by the ethnologist Manuela Carneiro da Cunha, and from the tacit knowledge of the artificer, by the philosopher Richard Sennett.

Keywords: Theater pedagogy; popular culture; pedagogical of the graduation course; theater teacher training; theater graduation

E-ISSN: 2358.6958

1 Prof. Dr. Universidade Federal de Alagoas (UFAL), nas áreas de Teatro Educação e Encenação. Doutor e Mestre em Artes Cênicas pela Escola de Comunicações e Artes (ECA) da Universidade de São Paulo (USP). margianini@hotmail.com 
O Projeto Pedagógico do Curso (PPC) de Teatro Licenciatura da Ufal (UFAL, 2014), implantado em 2015, reconhece as manifestações espetaculares da tradição popular como expressões teatrais norteadoras para a formação do Professor de Teatro que irá atuar na Educação Básica brasileira. A apresentação e a análise das propostas contidas neste PPC, e que ainda estão sendo colocadas em prática, são motivadas pela necessidade em se problematizar o ensino e aprendizagem do Teatro a partir do contexto cultural de sua inserção.

A necessidade de se construir um novo projeto pedagógico para a licenciatura em Teatro da UFAL visava a adequação do PPC às exigências da legislação educacional brasileira, criadas no interstício 2006-2014. Já a proposição política, educativa e estética de se olhar para as manifestações espetaculares da tradição popular como articuladoras na formação do Professor de Teatro em Alagoas foi amadurecida em reuniões ampliadas do Núcleo Docente Estruturante (NDE) do curso, das quais participava também o corpo discente, tornando-se este o fórum responsável pela elaboração do novo PPC.

Já nos primeiros encontros percebeu-se que, mesmo naquele reduzido fórum, havia visões distintas sobre o teatro e, consequentemente, uma pluralidade de perspectivas pedagógicas. Sendo um dos objetivos do curso, e talvez o principal no contexto alagoano, formar professores de Arte, não seria mais pertinente perguntar-se qual é o teatro que se faz na capital do estado, Maceió, e nas cidades do interior? Dessa maneira, em lugar de olharmos o teatro a partir dos indivíduos que fazem o curso, procuramos entender o que seria a linguagem teatral para a população alagoana. Nesse movimento, as respostas foram se distanciando daquele teatro de origem europeia e se dirigindo para as manifestações dramáticas e espetaculares da tradição popular alagoana.

Aqui, iremos sublinhar os pontos desta reforma que se referem ao seu conceito pedagógico e aos dilemas relativos a suas metodologias de aprendizagem, e que talvez possam problematizar a formação do Professor de Teatro no país.

\section{Uma perspectiva ampliada de teatro}

Ao reconhecermos as manifestações dramáticas e espetaculares da tradição popular alagoana e brasileira como formas de teatro norteadoras dos estudos e das pesquisas acadêmicas na formação de professores, propomos um entendimento ampliado sobre as fronteiras da linguagem teatral dentro da universidade. Estamos friccionando alguns conceitos e perspectivas do teatro, de suas pedagogias e daquelas voltadas à Educação Básica, para os quais não existem sínteses tranquilizadoras, mas tensões constantes.

O movimento em direção às formas artísticas da tradição popular de Alagoas, especificamente àquela que contêm elementos espetaculares e dramáticos, além do caráter político e de afirmação cultural, também vai ao encontro do artigo 26 , da LDB n 9.394, de 1996, que traz em seu texto, "§ 2 ㅇ O ensino da Arte, especialmente em suas expressões regionais, constituirá componente curricular obrigatório nos diversos níveis da educação básica, de forma a promover o desenvolvimento cultural 
dos alunos" (Brasil, 1996, grifo nosso)2. Para nossa proposta de curso, não se trata de negar as expressões e manifestações artísticas da tradição teatral, mas de legitimar a arte vinda da tradição popular alagoana tomando-a também como parâmetro para a formação do Professor de Teatro no estado de Alagoas.

Assim, sem perder o senso crítico da arbitrariedade de algumas destas proposições, o PPC estabeleceu como um dos objetivos da Licenciatura em Teatro da UFAL:

Formar docentes e pesquisadores teatrais capacitados para realizar mediações entre os conhecimentos da cultura da tradição popular alagoana e os conhecimentos da chamada cultura acadêmica, dando voz e reconhecendo os saberes dos mestres dessa tradição nos meios universitários e difundindo os saberes acadêmicos em comunidades sem acesso a esses, valorizando, assim, a diversidade cultural brasileira. (UFAL, 2014, p. 35, grifo nosso)

O movimento de busca, de pesquisa, de entendimento e, principalmente, do estabelecimento de um diálogo permanente com as formas teatrais da tradição popular levou-nos a traçar uma Caracterização Conceitual para o curso, através da qual se pretende formar o professor como "um mediador entre [...] dois modos de produção cultural, o popular e o acadêmico/erudito" (UFAL, 2014, p. 17).

Importante salientar aqui que não se pretende fazer distinções de valor entre estes modos de produção teatral, nem mesmo privilegiar um em detrimento do outro, visto que ambos comungam dos mesmos elementos que formam a linguagem teatral. O que se quer é criar canais de diálogo em que as formas e poéticas vindas da tradição popular, que têm em seus mestres os máximos representantes artísticos, tenham corpo e voz dentro da universidade e sejam reconhecidas e valorizadas como obras de arte e seus produtores como artistas. Por outro lado, também se deseja que a produção acadêmica e erudita possa ser democratizada sem se transformar em uma "monocultura colonizadora" do imaginário popular ou em uma cultura que se restrinja, em suas formas de produção e fruição, às elites econômicas. (UFAL, 2014, p. 17, grifos nossos)

Há uma preocupação constante em se criar um diálogo que evite a estigmatização e a guetificação dos conhecimentos locais e universais. O intercâmbio de saberes é fundamental para que não se estabeleça uma visão de cultura na qual a comunidade fique refém de sua própria produção artística. Para a etnóloga Manuela Carneiro da Cunha, é preciso distinguir cultura, enquanto categoria analítica, como "esquemas interiorizados que organizam a percepção e a ação das pessoas e que garantem um certo grau de comunicação em grupos sociais" (Cunha, 2009, p. 313), na qual o indivíduo é parte de um todo social, de "cultura" (com aspas) da qual supõe-se que as invenções são de autoria coletiva e na qual o discurso age "como recurso e como arma para afirmar identidade, dignidade e poder diante de Estados nacionais ou da comunidade internacional" (p. 373). Ou seja, na "cultura" a unidade deixa de ser o indivíduo para se constituir na própria comunidade. Assim, a ideia que perpassa todo o PPC é a de friccionar conceitos como patrimônio cultural da humanidade e manifestações artísticas oriundas das tradições populares, de cultura e "cultura", entre outros.

\footnotetext{
2 A expressão "especialmente em suas expressões regionais" foi acrescentada ao documento no ano de 2010, através da Lei n 2.287 , promulgada pelo presidente Luís Inácio Lula da Silva.
} 


\section{Um conceito criado a partir de negações}

Ainda que considerada necessária, a definição do que seriam estas manifestações artísticas das tradições populares não foi realizada no PPC porque, além de divergências entre os próprios professores, justificou-se que "se o que se quer é estabelecer diálogos, atritos e fricções entre a universidade e a comunidade, tal conceituação pode vir a ser uma restrição inicial a estes objetivos de interação e mediação" (UFAL, 2014, p. 18). Procurou-se, em lugar de um conceito fechado, identificar ou indicar um território, as formas de produção e, ainda, alguns elementos recorrentes, que nos auxiliam a traçar as fronteiras de nosso projeto.

O território a que nos referimos como Cultura Popular de Tradição de Alagoas sociologicamente refere-se àquelas manifestações artísticas vindas de camadas da população desfavorecidas economicamente e que habitam o território do estado de Alagoas. Tais manifestações não se limitam necessariamente a uma pressuposta origem alagoana ou se restringem ao que se possa chamar de "identidade alagoana", mas fazem parte do imaginário de uma comunidade estabelecida geograficamente neste território. (UFAL, 2014, p. 18)

Observe-se que na tentativa de identificar um território o documento comete o equívoco de "privatizar" as manifestações da tradição popular em uma determinada classe econômica, dando-lhe a exclusividade sobre essa produção artística e cultural. É importante observar que essas manifestações atravessam o imaginário popular sem se prender a categorias socioeconômicas. Assim, o que se pretende com este recorte é delimitar o campo no qual acontecem as manifestações artísticas sem necessariamente entrar em celeumas e debates sobre a origem histórica e geográfica das brincadeiras. O que nos interessa nessas manifestações são suas formalizações cênicas e seus modos pedagógicos de transmissão, hoje, dentro de suas comunidades. Não se descartam pesquisas históricas e etnográficas sobre as origens e trajetórias que as manifestações percorreram, porém parece-nos que essas abordagens poderiam nos levar a eleger determinados folguedos em prejuízo de outros a partir de juízos de valor externos à própria manifestação. Manuela da Cunha observa que o sentido de "autoria coletiva", muitas vezes presente em discursos de "identidade cultural", se deve a origem antropológica que se deu ao termo "cultura" e que este não deveria ser entendido de maneira totalizante:

O termo "cultura", em seu uso antropológico, surgiu na Alemanha setecentista e de início estava relacionado à noção de alguma qualidade original, um espírito ou essência que aglutinaria as pessoas em nações e separaria as nações umas das outras. Relacionava-se também a ideia de que essa originalidade nasceria das distintas visões de mundo de diferentes povos. Concebia-se que os povos seriam os "autores" dessas visões de mundo. Esse sentido de autoria coletiva e endógena permanece até hoje. (Cunha, 2009, p. 354, grifos nossos)

A etnóloga observa que não podemos nos restringir a esta perspectiva única de cultura, pois em quase todas as sociedades amazônicas, por exemplo, "costumes, cantos, cerimônias, saberes e técnicas têm por definição uma origem alheia" (Cunha, 2009, p. 360), ou seja, são exógenas. Para ela, não cabe na restrita imaginação das sociedades industrializadas "que povos inteiros [...] possam pensar suas culturas como exógenas, ob- 
tidas de outrem" (2009, p. 329), concluindo, dessa maneira, que a "'autenticidade' é uma questão indecidível" (Cunha, 2009, p. 343, grifo da autora).

Sendo nosso foco o teatro e a pedagogia, interessa-nos que o Professor de Teatro formado pela Ufal, quando no exercício da docência, possa olhar para a comunidade na qual está inserida sua escola e saiba detectar as manifestações teatrais ali presentes, trabalhando a partir delas, valorizando a voz, a presença e os saberes dos artistas e mestres locais, realizando a mediação destas formas com os estudos teatrais e as pesquisas desenvolvidas na vida acadêmica.

Nestes "territórios fluídos e passíveis de criação de novas fronteiras" (UFAL, 2014, p. 18), o PPC propõe algumas delimitações, ainda que construídas mais por negativas do que por assertivas:

\begin{abstract}
Os mestres populares, ainda que alfabetizados, dificilmente se expressam através de uma cultura letrada; transmitem seus ensinamentos de forma oral e reproduzem as formas e modos como eles próprios se formaram, ressaltando-se ainda que muitos sejam autodidatas. Sua arte é sua forma de expressão e produção de conhecimento. Essa expressão não tem o caráter de ineditismo ou de novidade, muitas vezes presente na arte erudita. Os materiais poéticos já estão formalizados pela tradição, através de gerações, o que não significa que não dialoguem com o mundo, em seus movimentos e transformações, gerando sempre novas formas de expressão e comunicação. Tal formulação nos afasta da conceituação folclórica que por ventura essas manifestações venham a carregar através do olhar estrangeiro a elas (estrangeiro aqui no sentido de estranho). Este olhar pressupõe que a manifestação artística esteja congelada no tempo e no espaço, e que suas formas e poéticas não são atualizadas, deixando de dialogar com o mundo. Nada mais distante do que pensamos. A cultura de tradição popular é, pois, uma cultura em constante transformação. (UFAL, 2014, p. 18, grifos nossos)
\end{abstract}

A propósito da oralidade na transmissão desse conhecimento da tradição popular, Richard Sennett observa que "o trabalho artesanal cria um mundo de habilidade e conhecimento que talvez não esteja ao alcance da capacidade verbal humana explicar" (Sennett, 2009, p. 111). Para este filósofo, a dificuldade em descrever em palavras os processos de produção revela mais os limites da linguagem do que a incapacidade de articulação do pensamento: "desarticulado não quer dizer burro; com efeito, o que somos capazes de dizer com palavras pode ser mais limitado que aquilo que fazemos com as coisas" (p. 111), sendo assim, "os limites da linguagem podem ser transcendidos pelo envolvimento ativo numa prática" (p. 112).

A expressão utilizada para a transmissão dos ensinamentos na "forma oral" se refere não à ausência de textos escritos, mas à impossibilidade mesma de transformar em linguagem escrita um conhecimento que é tácito e que só pode ser apreendido por meio do desenvolvimento de habilidades e de experimentações em contato com a própria matéria.

Outra delimitação do que seriam as manifestações da tradição popular refere-se ao caráter de suas formalizações e modos de transmissão já conhecidos, isto é, em princípio avessos ao ineditismo e à novidade. A perspectiva de arte como a reprodução perene do que se dá a ver não é uma singularidade da "cultura" popular alagoana e brasileira, pois pode ser encontrada, por exemplo, em manifestações teatrais clássicas do oriente. A questão talvez não se refira a um suposto conflito de "tradição versus inovação", mas 
na valorização da originalidade que remontaria, segundo Sennett, aos artistas renascentistas e que se transformaria em direito jurídico sobre a propriedade intelectual, na perspectiva de Manuela da Cunha.

Para Sennett, a valorização da originalidade resultaria na criação de uma distinção entre arte e artesanato: "[A arte] representa a concessão de um novo e mais amplo privilégio à subjetividade na sociedade moderna, com o artífice voltado para sua comunidade e o artista voltado para si mesmo" (Sennett, 2009, p. 80). A originalidade seria vista, assim, como característica dos indivíduos sozinhos, isolados, e a palavra arte passaria a designar obras únicas ou singulares, "ao passo que artesanato remete a práticas mais anônimas, coletivas e contínuas" (p. 81). O próprio Sennett assinala que "é preciso desconfiar desse contraste" (p. 81), pois a originalidade é um rótulo social, o que remeteria, a nosso ver, aos discursos sobre a arte e suas formas de recepção e catalogação, e não ao objeto artístico em si.

Manuela da Cunha, por sua vez, observa que "a construção contemporânea dos direitos de propriedade intelectual tem em sua base a noção romântica do autor criativo que constrói uma obra original ab nihilo" (Cunha, 2009, p. 367), o que se constitui em uma falácia que se aplica à criação artística e à invenção científica: "A concepção demiúrgica de uma autoria que parece baixar por inspiração divina omite as contribuições intelectuais coletivas e individuais em que se fundam a invenção e a criação" (p. 367).

O PPC de Teatro Licenciatura da Ufal procura, assim, reafirmar uma perspectiva ampliada sobre a linguagem teatral que possa nos possibilitar um olhar sobre o teatro que se faz no mundo a partir de suas próprias expressões, do que se dá a ver, e de seus modos pedagógicos, e não reduzi-los a categorias classificatórias e, por vezes, excludentes.

Categorizações que também detectamos na perspectiva folclórica que, em geral, procura normatizar as práticas, as poéticas e as formalizações estéticas das manifestações artísticas, estabelecendo o que é e o que não é característico de cada uma a partir de premissas construídas por meio de percepções externas aos próprios modos de produção. Esta perspectiva tende a tornar a própria manifestação refém de sua história e incapaz de se comunicar com seu tempo e contradiz a noção de conhecimentos tradicionais que vem se formando na "literatura jurídica", segundo Manuela da Cunha:

[...] os conhecimentos tradicionais não são simplesmente um corpus estabilizado de origem imemorial, e sim conjuntos duradouros de formas particulares de gerar conhecimentos. O conhecimento tradicional, segundo essa visão, não é necessariamente antigo. Tradicionais são seus procedimentos - suas formas, e não seus referentes. (Cunha, 2009, p. 364)

O que se observa nessas manifestações é que o novo (a novidade) é incorporado à brincadeira pela própria necessidade de comunicação em um processo dialógico intrínseco à própria comunidade, pois baseado em referenciais comuns e não como necessário para que a manifestação se realize. Registre-se, porém, que aqui não é possível estabelecer delimitações que se queiram totalizadoras, pois em manifestações como a quadrilha junina estilizada e o boi alagoano, que se organizam para apresentações em festivais competitivos, no estado de Alagoas, o que se valoriza são os elementos inéditos e as novidades incorporadas às apresentações anuais. 
Ao lado da negação da perspectiva folclorizante, soma-se ainda a recusa em utilizar o termo etnocenologia no documento. Segundo Patrice Pavis, esta nova disciplina "amplia o estudo do teatro ocidental para as práticas espetaculares do mundo inteiro, [...] sem projetar nessas práticas uma visão eurocêntrica" (Pavis, 1999, p. 152). Acreditamos, pelo contrário, que a necessidade em se criar uma disciplina para estudar o que não se enquadra no que se entende por teatro nesta perspectiva europeia denuncia, por si só, uma ação colonizadora das antigas metrópoles em relação a suas antigas colônias, para usarmos os termos de Manuela da Cunha: "categorias analíticas [...] fabricadas no centro e exportadas para o resto do mundo" (Cunha, 2009, p. 311). Utilizar o termo etnocenologia no PPC seria, para nós, naquele momento, reafirmar uma perspectiva que precisa adjetivar toda manifestação estética espetacular que não faça parte de sua própria tradição artístico-cultural. Ou seja, o parâmetro do que é teatro viria de um olhar estrangeiro à própria manifestação e o que não correspondesse a ele se tornaria um teatro "diferente" para o qual é necessário se criar uma nova disciplina de estudo.

A não utilização do termo etnocenologia no PPC não significa, entretanto, a discordância em relação à disciplina, pois reconhecemos que muitos estudos acadêmicos vêm sendo desenvolvidos a partir desta perspectiva e, como consequência, legitimando as formas teatrais oriundas da tradição popular. A omissão do termo se caracterizaria como uma tentativa de não se criar fronteiras e perspectivas muito rígidas que possam vir a se tornar uma nova forma de classificação normativa e que em lugar de abrir o mundo do teatro para o estudo e a experimentação de formas diversas, fecham-no em categorias, por vezes excludentes e totalizadoras.

Outra negação presente no PPC se refere ao termo artesanato, visto sob um possível rótulo depreciativo, para se referir às artes de tradição popular:

O teatro é, essencialmente, uma arte construída através do domínio técnico, portanto, por meio da artesania de seus criadores. Os rótulos de artesanato para as manifestações cênicas de tradição popular podem, em nossa opinião, se aproximar mais de uma cultura extrativista, como a dos grupos para-folclóricos, que muitas vezes se utilizam das formas expressivas populares para a produção de espetáculos inseridos em contextos mercadológicos, ainda que em seus discursos predominem os objetivos de preservação. (UFAL, 2014, p. 19, grifos nossos)

Percebe-se no texto uma confusão em relação ao termo artesanato, associando-o a uma intenção de desvalorização da obra por meio da qual se reconheceria nas manifestações da tradição popular uma expressão artística menor, sem autoria ou de autoria anônima. Parece-nos, hoje, que a negação ao termo artesanato está equivocada, pois o que se depreende do texto é outra negação: a de uma cultura chamada de extrativista que seria representada pelos grupos para-folclóricos. Talvez a confusão venha da associação de artesanato somente à reprodução de peças ad infinitum, cópias de cópias que perdem, aos poucos, seu valor de expressão artística limitando-se aos seus valores de troca.

O texto, por outro lado, procura valorizar e legitimar a artesania presente em todo processo artístico. Richard Sennett afirma que "em termos de prática, não existe arte sem artesanato; a ideia de uma pintura não é uma pintura" (Sennett, 2009, p. 79). Ou seja, o processo de criação artística envolve um fazer que é artesanal e que não está desprovido 
de pensamento, pois no embate com a matéria - no qual Sennett detecta a resistência e a ambiguidade como "experiências instrutivas" (Sennett, 2009, p. 21) - a obra é pensada/ criada.

No documento, "cultura extrativista" parece então se referir a ações que, ao não reconhecerem autoria nas obras da tradição popular no sentido da propriedade intelectual aludido por Manuela da Cunha, se apropriam dessas manifestações. Ou seja, pessoas e grupos em geral estranhos à comunidade que, mesmo não tendo participado da "plantação", "coletam" as formalizações artísticas e as transformam em "bens" negociáveis, seja no mercado acadêmico, no caso de pesquisadores que se arvoram o direito de propriedade intelectual sobre seus "achados", seja através de espetáculos de grupos para-folclóricos, ou mesmo os chamados "artísticos".

O que chamamos aqui de grupos para-folclóricos são aqueles organizados comercialmente e que reproduzem as manifestações artísticas da tradição popular realizando alterações em alguns de seus elementos para tornar mais "palatável" ao gosto médio seus espetáculos, atendendo a uma clientela de turistas, em hotéis e eventos ligados ao turismo. O que o PPC nega nesses grupos, que existem em abundância em Alagoas, é a homogeneização e padronização dos corpos dos atuantes e a estilização inconsequente de elementos da encenação. Entretanto, cabe observar que, por vezes, são justamente estes grupos que recuperam manifestações tidas como perdidas, criam interesse pelas manifestações originais e até mesmo podem se transformar em fonte de renda para as próprias comunidades.

Mais uma negação presente no PPC se refere a movimentos de preservação e de resgate das manifestações da tradição popular:

\footnotetext{
"Preservação" é outro conceito, ao lado de "resgate", com os quais não pretendemos utilizar na formação de nossos professores mediadores, ainda que vislumbremos a necessidade de trabalharmos com eles e que, provavelmente, nossas ações provoquem movimentos preservacionistas e de resgate de manifestações por desventura desaparecidas. (UFAL, 2014, p.19)
}

Acreditamos que os termos preservação e resgate carreguem um sentido conservador que procura retirar a obra de arte do mundo conferindo-lhe uma aura de pureza e de uma presumível autenticidade que a impede de continuar agindo entre os homens. Manuela da Cunha observa que os instrumentos internacionais ainda tratam o conhecimento tradicional

[...] como um thesaurus, isto é, um conjunto completo e fechado de lendas e sabedorias transmitidas desde tempos imemoriais e detidas por certas populações humanas, um conjunto de saberes preservados (mas não enriquecidos) pelas gerações atuais. Note-se que uma concepção como esta enviesa as políticas públicas na direção do "salvamento". O que passa a importar não é a conservação dos modos de produção dos conhecimentos tradicionais, e sim o resgate e a preservação desses thesaurus, que se compararam a outras tantas "Bibliotecas de Alexandria". (Cunha, 2009, p. 364)

Trata-se, assim, de retirar das manifestações da tradição a potência transformadora que toda obra de arte carrega em si, em um movimento que deslegitima o próprio conhecimento ali produzido. Como dito mais acima, os procedimentos e formas podem ser 
tradicionais, mas não o são seus referenciais, os quais, através de um processo dialógico, constituem-se em "formas particulares de gerar conhecimentos" (Cunha, 2009, p. 364).

\section{A arte e a pedagogia do brincante}

Ao tomarmos os mestres da cultura popular como referência e suas obras como parâmetro para o ensino da linguagem teatral e para a formação do Professor de Teatro, dois aspectos relevantes precisam ser considerados: a diversidade de linguagens artísticas presentes em suas produções e as formas de transmissão de sua arte.

O mestre não só conhece toda a brincadeira, mas sabe como fazer e como transmitir; possuindo o domínio técnico, poético e pedagógico de sua arte. Ele está presente em todos os momentos da produção (Sennett, 2009, p. 90-1) e, neste sentido, podemos reconhecê-lo como um multiartista que transita por todas as linguagens que compõem o universo de sua brincadeira.

Sua forma múltipla de agir no mundo através de sua arte é similar à formação que propomos para o Professor de Teatro, isto é, o domínio dos elementos que compõem a cena e sua pedagogia. A complexidade presente na arte do mestre da cultura popular abole fronteiras de linguagens, constituindo-se em formas híbridas trabalhadas com apurado domínio da composição. Seu caráter coletivo faz com que o olhar do mestre seja o olhar do todo.

A pedagogia dos mestres da tradição popular problematiza a própria metodologia de ensino e aprendizagem presente no PPC, pois, como citado, eles "transmitem seus ensinamentos de forma oral e reproduzem as formas e modos como eles próprios se formaram" (UFAL, 2014, p. 18).

[...] a caracterização conceitual do curso, marcada pelo diálogo com o contexto cultural no qual está inserido, coloca uma questão de natureza pedagógica, da qual a metodologia exposta acima não poderá deixar de enfrentar. Ao optar por uma ação de mediação entre a cultura de tradição popular e a cultura acadêmica no plano estético, torna-se necessário também realizar ações de mediação no plano pedagógico.

Problematizar, sob uma perspectiva crítica, os procedimentos de ensino-aprendizagem e as práticas didáticas desses ambientes culturais, em que a construção do conhecimento é realizada por meio de ações pedagógicas distintas, é colocar em questão a própria metodologia do curso apresentada até aqui. Baseada em situações-problema, na ação-reflexão-ação e na prática dialógica, a pedagogia do aprender a aprender, preconizada pelas DCN [Diretrizes Curriculares Nacionais] para os cursos de licenciatura, foi construída no embate contra as pedagogias tradicionais, baseadas na transmissão de formas e conteúdos, saberes e técnicas, nas quais se inserem a arte, a pedagogia e a cultura de tradição popular. Reconhecer este paradoxo significa problematizar os paradigmas da educação preconizados pela Unesco e referendados pelo MEC para este terceiro milênio. O processo pedagógico de formação do professor de teatro, que objetiva a atuação deste como mediador entre estas culturas, deve explicitar e problematizar esta contradição, sob o risco de, ao negá-la, falsear a própria mediação e atuar mais uma vez de forma colonizadora culturalmente e de forma extrativista do patrimônio material e imaterial destas populações desfavorecidas economicamente. (UFAL, 2014, p. 45) 
Ainda que sem apresentar propostas ou caminhos para se estudar de forma "crítica" como fazer a mediação entre o pensamento dominante de práticas de ensino vindas das pedagogias do "aprender a aprender", disseminadas no sistema educacional brasileiro, e as pedagogias oriundas da tradição popular, baseadas na transmissão dos saberes, o documento reconhece o paradoxo e a necessidade de se enfrentar a questão.

\section{Perspectivas e dilemas}

Mesmo reconhecendo no novo PPC de Teatro Licenciatura da Ufal perspectivas significativas na formação do professor de Teatro para a Educação Básica brasileira, divisamos também alguns dilemas a serem enfrentados. $O$ primeiro se refere aos objetos de estudo e experimentação e às suas formas diferenciadas de produção, pois cada manifestação artística da tradição popular possui suas peculiaridades e nem todas possuem um mestre que conduza e oriente as ações da comunidade, como é o caso, por exemplo, de diversos grupos de Quadrilhas juninas estilizadas e de Bois alagoanos. Inseridos em uma produção voltada aos festivais competitivos e ao calendário turístico de Alagoas, a noção de transmissão de um saber tradicional por vezes é substituída pela necessidade de executar "corretamente" o que foi determinado por um artista criador. Aqui, o dilema se refere na maneira de abordar diferenças que não correspondem ao idealizado no PPC, pois quando tentamos delimitar um território para o que se entende como Cultura Popular de Tradição de Alagoas, corremos o risco de recriar um ideal de "pureza" presente em visões rejeitadas no próprio documento.

Outro dilema se refere aos modos pedagógicos conflitantes entre as manifestações da tradição popular e as pedagogias do "aprender a aprender", citado acima. Pergunta-se: um processo de ensino e aprendizagem de expressões artísticas oriundas da tradição popular dentro da escola formal, seja em cursos superiores, seja na Educação Básica, realizado a partir da perspectiva de construção do conhecimento seria uma maneira de "trair" o próprio objeto de estudo, acolhendo suas formalizações, porém rejeitando seus modos de produção e transmissão?

A primeira turma a trabalhar dentro deste novo PPC, ingressante no curso em 2015, ainda está em formação, o que faz com que avaliações sobre o alcance e a eficácia das propostas sejam extremamente prematuras. O que se pode expor, por ora, são primeiras observações surgidas a partir da experiência que passamos e que nos atravessa. De um lado, alguns docentes e discentes questionam a indistinção conceitual entre as manifestações espetaculares da tradição popular e o teatro de tradição europeia, o que nos faz refletir se o sentido alargado para a linguagem teatral, proposto no PPC, não corresponda ao um desejo de legitimação das primeiras a partir, mais uma vez, de um olhar colonizado. Sublinhe-se também a dificuldade que encontramos diante da administração de dinheiro público para o pagamento de cachês ou mesmo de ajudas de custo aos mestres e aos grupos populares para apresentações dentro da universidade. 
Por outro lado, vemos que as brincadeiras e folguedos tomaram os espaços de aula e de apresentações públicas do curso como seus lugares legítimos de expressão, diferente do que ocorria anteriormente, quando pareciam "pedir licença" para pisar nos pátios da universidade. Alguns grupos de Boi e de Coco alagoanos, ao perceberem o interesse da academia por elementos de sua arte que estavam sendo "esquecidos", passaram a repensar suas formas de apresentação nos concursos e festivais. 0 mesmo ocorre, porém em menor grau, com as Quadrilhas juninas estilizadas, devido a participação de alunos do curso em vários desses grupos da cidade de Maceió. Percebe-se também o aumento de projetos de extensão que têm as manifestações da tradição popular como objeto de estudo e difusão, bem como se anunciam projetos de Trabalho de Conclusão de Curso sobre esta temática. Porém, reafirmem-se, estas são primeiras observações que merecem, num futuro próximo, um estudo aprofundado, mas que podem indicar as perspectivas que este Projeto Pedagógico do Curso de Teatro Licenciatura da Ufal pode trazer para as pesquisas sobre a formação do Professor de Teatro no Brasil.

\section{Referências}

BRASIL. Lei de Diretrizes e Bases da Educação Nacional. Lei no 9.394. 20/12/1996.

CUNHA, Manuela Carneiro da. "Cultura" e cultura: conhecimentos tradicionais e direitos intelectuais. In: Cultura com aspas e outros ensaios. São Paulo: Cosac e Naify, 2009.

PAVIS, Patrice. Dicionário de teatro. Tradução sob a direção de J. Guinsburg e Maria Lúcia Pereira. 2. ed. São Paulo: Perspectiva, 1999 (reimpressão 2003).

SENNETT, Richard. O Artífice. Tradução de Clóvis Marques. Rio de Janeiro: Record, 2009.

UFAL. Projeto Pedagógico do Curso de Teatro Licenciatura. Universidade Federal de Alagoas. Instituto de Ciências Humanas, Comunicação e Artes, 2014. Disponível em: http:// www.ufal.edu.br/estudante/graduacao/projetos-pedagogicos Acesso em: 13 abr. 2015.

Recebido em: 31/10/2018

Aprovado em: 10/01/2019 